\title{
BME Career Exploration: Examining Students' Connection with the Field
}

\author{
Cassandra Sue Ellen Jamison (10, ${ }^{1}$ Annie AnMeng Wang, ${ }^{1}$ \\ Aileen Huang-SaAd (iD, ${ }^{2}$ Shanna R. Daly $\left(\mathbb{D},{ }^{3}\right.$ and Lisa R. Lattuca (D) ${ }^{4}$ \\ ${ }^{1}$ Department of Biomedical Engineering, University of Michigan, Ann Arbor, MI, USA; ${ }^{2}$ Department of Bioengineering, The \\ Roux Institute, Northeastern University, Portland, ME, USA; ${ }^{3}$ Department of Mechanical Engineering, University of Michigan, \\ Ann Arbor, MI, USA; and ${ }^{4}$ Center for the Study of Higher and Postsecondary Education, University of Michigan, Ann Arbor,
} MI, USA

( Received 22 June 2021; accepted 18 October 2021; published online 28 October 2021)

\begin{abstract}
A common perception of biomedical engineering (BME) undergraduates is that they struggle to find industry jobs upon graduation. While some statistics support this concern, students continue to pursue and persist through BME degrees. This persistence may relate to graduates' other career interests, though limited research examines where BME students go and why. Scholars are also pushing for research that examines engineering careers in a broader context, beyond traditional industry positions. This study adds to that conversation by asking: How do BME students describe their career interests and perceived job prospects in relation to why they pursue a BME degree? A qualitative study of BME students was performed at a public, R1 institution using semi-structured interviews at three timepoints across an academic year. An open coding data analysis approach explored careerperceptions of students nearing completion of a BME undergraduate degree. Findings indicated that students pursued a BME degree for reasons beyond $\mathrm{BME}$ career aspirations, most interestingly as a means to complete an engineering degree that they felt would have interesting enough content to keep them engaged. Participants also discussed the unique careerrelevant skills they developed as a BME student, and the career-placement tradeoffs they associated with getting a BME undergraduate degree. Based on these results, we propose research that explores how students move through a BME degree into a career and how career-relevant competencies are communicated in job searches. Additionally, we suggest strategies for BME departments to consider for supporting students through the degree into a career.
\end{abstract}

Address correspondence to Aileen Huang-Saad, Department of Bioengineering, The Roux Institute, Northeastern University, Portland, ME, USA. Electronic mail: a.huang-saad@northeastern.edu
Keywords-Biomedical engineering, Career-relevant skills, Career exploration.

\section{INTRODUCTION}

The first biomedical engineering (BME) programs began with engineers who were interested in solving interdisciplinary problems at the interface of engineering, biology, and medicine. ${ }^{21}$ This interest in solving interdisciplinary problems links strongly to BME program curricula, particularly at the undergraduate level. BME undergraduate programs across the United States have created curricula that are intentionally broad and diverse, which has allowed students to pursue a wide variety of careers upon graduation. ${ }^{1,19,31}$ However, the diversity and breadth of topic areas covered in curricula from program to program has been criticized in relation to preparing students for BME-related careers, particularly for those in industry. ${ }^{2,3,12}$ Further, measures related to industry competitiveness, such as co-op or internship opportunities, BME graduate to BME industry job availability ratios, and average BME graduate salaries, show a disadvantage to BME students, and thus, support these critiques. ${ }^{2,7,21,24}$

While industry-focused studies have indicated that research should explore how BME educators can support students pursing industry positions upon graduation, they often do not consider the many other career interests and pathways of BME graduates. ${ }^{31}$ Recent research indicates that BME students are less likely than their peers in other engineering disciplines 
to pursue engineering industry careers, ${ }^{7,29}$ which has implications for how universities support student career exploration and placement in BME. Currently, career placement discussions in the BME education literature have focused on careers in industry or placement in graduate-level programs (e.g., medical school, Ph.D. programs, etc.), ${ }^{11,29}$ leaving other postgraduate career options such as consulting or clinical BME work underexplored. Given the increasing research that shows BME students are considering career options outside of engineering industry positions, it is important to also understand how those students navigate a BME undergraduate degree.

A greater understanding of why students pursue BME in relation to their career goals can inform how BME programs advertise to attract students, how programs support students in career exploration, and how programs develop strategic partnerships with BME graduate employers. This study employed qualitative methods to understand more about upper-level students' motivations for pursuing a BME degree in relation to career goals by asking questions about students' perceptions on BME career outlooks and the value they place on pursuing and receiving a BME undergraduate degree. This study extends related work of a recently published paper that found that BME undergraduate students entered their third year with a relatively narrow view of career possibilities and valued opportunities to explore their options through multiple avenues available at the university. ${ }^{13}$

\section{BACKGROUND}

Characterizations of BME in the literature often focus on its relationship to both engineering and medicine as well as the need to perform work that integrates knowledge from both disciplines to solve medical problems. ${ }^{1,27}$ The broad scope in how the BME discipline has been defined has allowed BME bachelor's degree graduates to pursue various careers upon graduation. According to one article, BME graduates with a bachelor's degree can secure entrylevel engineering positions in medical device or pharmaceuticals, clinical engineering in hospitals, biomaterials or biotechnology sales, academic institutions as researchers, and government agencies. ${ }^{31}$ The wide-array of career opportunities available in BME also means that BME professionals are tasked with a wide variety of job responsibilities. ${ }^{1}$ Biomedical engineers may be asked to design instrumentation, medical devices, or software. They may also be tasked with integrating technical knowledge from multiple sources to develop new procedures or conduct research to solve clinical problems. ${ }^{1}$ The breadth of careers linked to
BME as a discipline has had a strong influence on what BME curricula has evolved to be today.

The first formal BME programs launched in the 1960s as master's and PhD programs. ${ }^{21,27}$ Trailing the development of graduate programs, the first undergraduate programs began in the 1970s and 80s. As more BME undergraduate programs were established, discussions surrounding core courses or competencies also began. Two key initiatives had major impacts on the development of today's BME undergraduate programs. The first major initiative was VaNTH (a team of researchers from Vanderbilt, Northwestern, the University of Texas, and the Health Science and Technology program, which was jointly sponsored by Harvard University and MIT), a National Science Foundation engineering research center focused on BME education. Initially, VaNTH aimed to identify a set of core or foundational competencies in BME to help structure BME curricula across institutions. ${ }^{1}$ The second major initiative was organized by the Whitaker Foundation in 2000 - the first Biomedical Engineering Education Summit where the international community sought to develop a common understanding of BME curricula. At the meeting, the group determined that a single 'optimal' BME curriculum was not possible nor desirable. Participants emphasized the need for institutions with BME programs to prioritize the institution's strengths (based on faculty expertise, resource availability, etc.), while also providing rigorous engineering and life sciences education. ${ }^{1}$

As discussions of BME education have continued, diversity and flexibility in program structure has been a common theme. ${ }^{27}$ However, while the field moves towards consensus on the need for diverse and flexible programs, two BME educational dilemmas have yet to be settled. First is a question of breadth vs. depth in technical engineering content: Is depth (linked with older engineering disciplines like mechanical or electrical engineering) or breadth (linked to more interdisciplinary disciplines like general or industrial engineering ${ }^{15}$ ) most beneficial for students entering BME careers? The second dilemma is a question of program orientation: Should BME orient curricula toward practice (often industry positions in sectors such as medical devices, pharmaceuticals, biotechnology, etc.) or research (often academic or government positions $)^{14}$ ? Understanding the tradeoffs associated with these dilemmas from multiple viewpoints (e.g., university educators, administrators, students, industry stakeholders) has the potential to inform how programs prepare their graduates.

As institutions were first creating BME undergraduate programs, industry careers (e.g., in research and development, design, manufacturing, etc.) were a promising career pathway for graduates because the 
number of degrees granted was less than the number of available industry careers as a biomedical engineer in the 1970s and 1980s. ${ }^{1}$ However, as more BME programs are being developed and graduate numbers increase, this ratio is becoming less promising for graduates interested in industry jobs. Additionally, research has indicated that the evolution of a BME undergraduate curriculum that is intentionally broad may further limit BME graduates' industry career options upon graduation due to negative industry perceptions of graduate preparedness. ${ }^{1,6,18,24}$ Other research attributes these negative perceptions to industry's lack of understanding of what competencies and content knowledge they can expect from BME graduates. ${ }^{27}$ Acknowledging the diversity of content covered from program to program, some institutions have begun to explore the need to address the industry disconnect directly, citing a need to better market their students and train them to communicate their unique skills. ${ }^{18}$ One effort to address this disconnect that has shown particular promise is the development of co-op and internship partnerships, which better connect BME graduates to industry. However, these partnership programs are often labor, finance, and time intensive. ${ }^{35}$ Additionally, these partnerships are contingent on building a relationship between one BME program and a specific company. Evidence that would indicate that this approach can positively impact BME graduates more broadly (i.e., career placement for BME graduates not from a university with industry partnerships) is limited.

While it is important to consider how educators can better support BME students interested in pursuing industry positions given these concerns, recent exploratory work indicates that many BME students may instead or also be considering non-engineering or nonindustry career pathways upon graduation (e.g., K-12 education, government, non-profit, etc.). ${ }^{7,8,26,29}$ Some general research on engineering career pathways showed that students who complete an engineering degree program do not always pursue engineering careers. One such study that collected data from engineering majors at two institutions found that completing an engineering degree was not always linked to a commitment to perform engineering work. ${ }^{17}$ Within the context of BME, Rohde and colleagues found that an interest in BME was negatively associated with the desire to pursue an engineering industry career. ${ }^{29}$ Gilmartin and colleagues' exploration of the Academic Pathways of People Learning Engineering Survey (APPLES), found patterns that indicate BME students, when compared to other engineering disciplines like aerospace, chemical, civil/environmental, computer, electrical, industrial, and mechanical, are less likely to pursue engineering industry positions. ${ }^{7}$ They interpreted these patterns as an indicator that BME graduates may view their degrees as bridges to other positions (e.g., medical school or other professional programs). Some other exploratory research indicates that students may pursue BME as a means to combine engineering with other career interests (e.g., clinical careers ${ }^{8}$ or careers that serve or help others $\left.^{26}\right)$.

Research on BME undergraduate student pathways has largely focused on where students go upon graduation, often highlighting industry careers as a key career pathway upon graduation. ${ }^{11,29}$ Further, the emphasis on industry careers in BME may be limiting graduates' perspectives about possible careers they could pursue upon graduation. Rohde and colleagues support a similar view of engineering education, arguing that earning an engineering degree should be viewed as gaining skills that give students the ability to make a significant and meaningful impact in the workforce, even if they do not enter or persist in a career that is typically classified as engineering. ${ }^{30}$ While research is beginning to understand where students go upon graduation, there is still limited research on why students choose BME, what sort of careers they are interested in, or why they choose to pursue certain careers upon graduation. Research examining students' rationale for pursuing BME can provide important insights on a common understanding of what is possible, interesting, or important for students when choosing a major and subsequently a career upon graduation. These insights could inform program advertisements, career mentoring efforts, or company co-op and internship partnerships within a department. This study aims to contribute to that work by examining a set of BME student experiences in depth, offering suggestions for department-level programming and future research in this area.

\section{STUDY DESIGN}

This study was guided by the following research question:

How do BME students describe their career interests and perceived job prospects in relation to why they pursue a BME degree?

We leveraged a qualitative interview approach to address the research question of this study. Qualitative methods were beneficial for this study because the goals of the study aligned with the strengths of a qualitative approach to data collection and analysis. ${ }^{16,23}$ Qualitative research is flexible and allows a researcher to adjust their research approach to align with the ongoing research process (e.g., adding or adjusting research questions, adding interview questions, adjusting analytical approach). ${ }^{5}$ This approach 
to research was also relevant in this study because the refinement of questions allowed for the addition of a research question to the project which explored a phenomenon that was not originally within the scope of the interviews' goals. Identifying discussions about career prospects and BME degree value early in the study allowed us to explore a research question that was potentially important to understanding the degree and career perceptions of BME students.

The qualitative interview data in this paper were collected as part of a three part, year-long longitudinal study that examined the experiences of upper-level BME students in co-curriculars at a large R1 university and was determined as exempt by the institution's review board (HUM00168130). One goal of the interviews was to understand BME students' professional development through co-curricular engagement (which is outside the scope of what is reported here). However, this goal to investigate co-curricular engagement affected our recruitment strategy of inviting students to participate in interviews who were engaged in one or both of the following co-curricular settings: a multidisciplinary design team aimed at solving BME problems and undergraduate research. This participant sample also allowed us to investigate students' decisions to pursue a BME degree and their plans for their future careers.

During preliminary analysis of the first interviews, the first author noticed that students' comments seemed to relate to why they pursued their degree in relation to future careers. Follow-up questions to probe BME degree and career perceptions more directly were then added to the subsequent interview protocols. Refining (by adding or adjusting) research questions is a common approach in qualitative studies, which stress ongoing data collection and the interconnectedness of the multiple stages of research (e.g., literature review, research questions, methods selection, data collection, data analysis, and write up). ${ }^{5}$

\section{Institutional Context}

The institution where data were collected was a large, research-oriented, public university in the Midwest United States. At the time of article submission, the enrollment in the BME program was approximately 400 students. Of those enrolled, approximately $56 \%$ of them identified as female and $16 \%$ had a historically marginalized racial or ethnic identity in engineering. The BME students in this study selected one of three concentrations to pursue within the major: bioelectrical ( $11 \%$ of students), biochemical ( 58\% of students), or biomechanical ( $31 \%$ of students), however, the program recently transitioned to a broader track-based system for concentration areas.
To complete their concentration, students in this study selected 14 concentration specific credit hours of 128 total credit hours required to complete a BME degree. Recent data collected from an alumni survey indicates that approximately $26 \%$ of graduates enroll in medical school, $45 \%$ go into industry or government jobs, while the remaining $29 \%$ pursue other career pathways (e.g., consulting, social work, other post-secondary education, law, etc.). Due to the timing of the study (in the 2019-2020 academic year), the final interviews occurred after classes had moved to a fully remote format in response to the COVID-19 pandemic.

\section{Participants}

A set of participants were identified for the full study based on their academic standing (i.e., thirdyears) and participation in co-curricular activities of interest (criterion-based, purposeful sampling). ${ }^{22}$ To expand the participant pool, snowball sampling was employed by asking participants to identify others meeting the criteria who might be interested in participating. ${ }^{22}$ In studies where potential participants are difficult to identify or gain access to, snowball sampling is a common strategy to reach participants. ${ }^{9}$ Snowball sampling was employed in the full study to identify potential participants in the targeted co-curriculars, and especially those in undergraduate research, where students can participate in multiple capacities that are difficult to track at a departmental level (e.g., for credit, through university programming, for pay, or as a volunteer). Some researchers have critiqued snowball sampling based on the possibility of recruiting a sample that is not representative of the population of interest. ${ }^{9}$ In consideration of these concerns for the research question posed in this study, saturation (i.e., redundancy in the themes generated) was used as an indicator that the purposeful, snowball sampling approach was sufficient to explore the research question as it was posed for BME students in this particular context. ${ }^{22}$

Overall, the study recruited 14 BME undergraduate students at the beginning of their third year. Fourteen participants is within the range considered to be a typical sample size for a qualitative study, which aims for depth of understanding, not generalizability. ${ }^{9,23,33}$ Participants varied by self-reported gender, race and ethnicity, and intended concentration (summarized in Table 1). To protect the confidentiality of participants, direct quotes have been given a code where $\mathrm{P}$ (participant number)I(interview number) indicates a given participant and the interview in which participants said the quoted material. As an example, the first interview completed by the first student is referred to as P1I1 within the context of this study. 
TABLE 1. Participant demographic data $(n=14)$.

\begin{tabular}{lll}
\hline Gender & Race/ethnicity & Concentration \\
\hline Female (11) & Asian (6) & Biochemical (6) \\
Male (3) & Hispanic/Latinx (2) & Biomechanical (6) \\
& White/Caucasian (6) & Undecided (2) \\
\hline
\end{tabular}

\section{Interviews}

A series of three 45 to $90 \mathrm{~min}$ semi-structured interviews were conducted over the academic year by the first author, a BME graduate student, at the beginning of the participants' first semester (I1), the end of the first semester (I2), and at the end of the second semester of their third year (I3). Interviews were recorded and transcribed verbatim, with identifiable information redacted following transcription. All 14 participants completed I1 and I2. Thirteen participants completed I3.

As part of the larger study goal, semi-structured interviews were conducted to explore student perceptions of their professional development through their participation in co-curricular activities. The particular advantage of semi-structured interviews for this study was the flexibility of the questions asked. Typically, in a semi-structured interview, the interviewer asks all participants a series of questions, which facilitates comparisons across participants and time points; however, the interviewer also has flexibility in the interview to ask follow-up questions to further explore participants' views on a topic. ${ }^{16}$ Follow-up questions about participants' perceptions of the BME job market were added during the first interviews to explore the research question posed in this paper. These questions were then added to the interview protocol in I2 and I3. The discussions from those questions were extracted from the interviews and analyzed for this study.

\section{Data Analysis}

Interview sections that mentioned students' views of the BME degree or their perspectives on career placement were selected from the interview transcripts and compiled into NVivo 12, a software commonly used to organize and label qualitative data as part of the analysis process. ${ }^{25}$ The first two authors read through the interviews, identifying common areas of student discussion in the data, and agreeing on three foci (personal value, unique skills, and perceptions of career placement) to analyze in more depth. This process of reviewing the data and identifying broad topic areas to explore more in depth aligns with holistic coding approaches in qualitative data analysis. ${ }^{32}$ (pp. 166-168) Then, the first author analyzed the focus areas inductively, identifying themes in each. A values coding approach, which applies codes that aim to represent individuals' perspectives, was used to inform the identification of the themes presented. ${ }^{32}$ (pp. 131-136). This approach was helpful in identifying the values and beliefs students had about pursing a BME degree and subsequent career. The first two authors discussed these themes to reach consensus. ${ }^{10}$ Themes could be mentioned multiple times by a participant within one interview; however, in looking for patterns across time as presented in the results section, a theme was counted only once per interview. This strategy allowed the research team to look at how many participants discussed a theme at least once throughout the three interviews as well as look at how consistently themes were discussed by students when asked the same questions over time.

\section{Addressing Qualitative Research Quality}

One approach to establishing the quality of a qualitative research study, specific to engineering education research, is a process-oriented framework that addresses validity in all stages of the research study. ${ }^{34}$ The framework describes five validation constructs (theoretical, procedural, communicative, pragmatic, ethical) that pose questions for researchers to consider to achieve research quality from the making data to the handling data stages of a study (see Table 2 for descriptions of each validation construct). Throughout this study, the researchers engaged in reflective practices to ensure quality and to improve the reliability of the research process. Efforts that align with each of the validation constructs are also included in Table 2. By aligning conversations of quality with the framework developed by Walther and colleagues, qualitative researchers can clearly communicate the steps taken throughout the research process to ensure reliable, high-quality research. ${ }^{34}$ In doing so, they can also improve the understanding of quality qualitative research in the broader engineering education community.

\section{RESULTS}

Three common areas of focus were identified in participants' discussions about career prospects and the value of their degrees. The first focus related to the 
TABLE 2. Five types of process validation in qualitative engineering education research. ${ }^{34}$

\begin{tabular}{|c|c|c|}
\hline Validation & Description & Study efforts \\
\hline Theoretical & $\begin{array}{l}\text { Concerns the fit between the social reality under inves- } \\
\text { tigation and the theory generated }\end{array}$ & $\begin{array}{l}\text { The interviewer noticed discussions by participants about job } \\
\text { prospects and concerns about employment in the first } \\
\text { interviews of the full study. In order to probe these ideas } \\
\text { further, the interviewer added questions about these per- } \\
\text { ceptions in Interviews } 2 \& 3 \text { in order to gain a deeper } \\
\text { understanding of the phenomenon observed }\end{array}$ \\
\hline Procedural & $\begin{array}{l}\text { Concerns features of the research design that inherently } \\
\text { improve the fit between the reality studied and the } \\
\text { theory generated }\end{array}$ & $\begin{array}{l}\text { The students in this study were recruited for a project on pro- } \\
\text { fessional development through co-curricular experiences; } \\
\text { however, during data collection an additional research } \\
\text { question was developed for this study to explore BME stu- } \\
\text { dents' career perceptions more broadly. When adding the } \\
\text { research question, the research team reflected on the match } \\
\text { between the study sample and institutional population, con- } \\
\text { sidering what claims could be made from the data throughout } \\
\text { analysis } \\
\text { In looking at participant responses to the same questions } \\
\text { across time, the research team was able to gain insights into } \\
\text { perceptions that were frequently discussed which could } \\
\text { indicate the relative importance of themes in the data }\end{array}$ \\
\hline Communicative & $\begin{array}{l}\text { Concerns the integrity of the interlocking processes of } \\
\text { social construction with the relevant communication } \\
\text { communities }\end{array}$ & $\begin{array}{l}\text { By providing a thorough description of the study context and } \\
\text { participants, the research team aimed to provide other } \\
\text { researchers insights into if the work would be transferable to } \\
\text { their context. In qualitative research, rich description is a } \\
\text { common practice to allow other researchers to determine the } \\
\text { relevance of the findings in their own context } \\
\text { Additionally, examples of how participant responses were co- } \\
\text { ded were provided to increase the transparency of the } \\
\text { analysis process, which allows readers to determine if they } \\
\text { agree with how data were organized and analyzed }\end{array}$ \\
\hline Pragmatic & $\begin{array}{l}\text { Concerns the compatibility of theoretical constructs with } \\
\text { empirical reality }\end{array}$ & $\begin{array}{l}\text { Pragmatic validation was considered in the analysis and } \\
\text { interpretation stages of the research, where the research } \\
\text { team carefully considered the conclusions that could be } \\
\text { drawn from the context of this study. As such, discussion of } \\
\text { results focuses on findings that have not been presented on } \\
\text { the topic previously and suggests future research based on } \\
\text { each of the themes presented in the results }\end{array}$ \\
\hline Ethical & $\begin{array}{l}\text { Concerns aspects of integrity and responsibility } \\
\text { throughout the research process }\end{array}$ & $\begin{array}{l}\text { Data analysis and interpretation stages engaged researchers } \\
\text { at multiple levels of their BME careers (a second-year } \\
\text { undergraduate student who recently declared BME, a fourth- } \\
\text { year BME PhD student, and a BME faculty member with } \\
\text { industry experience). In doing so, conversations during the } \\
\text { analysis phase addressed the relevance and accuracy of the } \\
\text { themes presented from multiple perspectives }\end{array}$ \\
\hline
\end{tabular}

personal value participants placed on their degree. In particular, participants described values beyond how the degree related to attaining a future BME career (i.e., how they described the value of the degree, regardless of their intention to stay in a career they perceived as BME). Focusing on the career placement value participants attributed to the degree, the second focus area identified some unique skills participants felt they had gained by pursuing a BME degree. Themes in the third focus area also related to career placement for students, identifying what participants described as perceptions of BME graduates. Participants discussed negative interpretations of these perceptions as possible barriers to a successful BME career search because of their choice of major; however, participants also frequently cited ways to positively interpret these perceptions during a career search.

\section{The Personal Value of an Undergraduate BME Degree}

Participants frequently described reasons for pursuing BME that did not directly relate to BME career placement (i.e., getting a job that they considered to be a BME career). Instead, the authors identified themes that captured how participants perceived how they personally could find value in the degree even if they were questioning their interest in pursuing what they 
thought a BME career was. These themes related to how the status associated with the degree (either engineering in general or the program at their institution specifically) and its curricular content played a role in their persistence in the degree. Three themes related to these personal values emerged from a deeper analysis of the data. These themes indicated that, beyond the value related to BME career aspirations, students also valued their BME degree for the following reasons:

Personal Value 1: Engineering is a valuable degree for pursuing a career in many fields.

Personal Value 2: The university I go to is well known for BME, which will help me in my future career goals.

Personal Value 3: The connection to biology or improving human life made engineering content interesting.

Half of the participants mentioned that an engineering degree in general (Personal Value 1) was valuable for their future goals in at least one interview, regardless of their current career aspirations. This indicated the relatively high value participants in this study place on engineering degrees in general. A similar pattern concerned how participants discussed the value associated with a BME degree from the specific institution they attended (Personal Value 2), specifically as it related to prestige or recognition of the particular university where the study took place. A smaller number of participants overall discussed the third personal value theme, the value of BME subject matter in keeping them engaged in an engineering field, in at least one interview $(n=5)$; however, the highest number of participants consistently named curricular content as valuable across all three interviews $(n=3)$. Table 3 shows example quotes of each theme along with the number of participants who discussed the theme in at least one interview or across all three interviews.

\section{The Unique Skills Gained Through a BME Degree}

When asked to discuss the value of their degree when applying for a job, participants named four skills that they thought made them highly qualified for jobs in BME. Participants discussed the kind of work they thought they would be performing in teams, across disciplines, and in the context of problem solving. Based on those characterizations of general BME work, participants described biomedical engineers as having the unique ability to:

TABLE 3. Examples of participants' personal values of having a BME degree.

\begin{tabular}{|c|c|c|c|}
\hline Theme & Example quote & $\begin{array}{c}1+ \\
\text { mention }\end{array}$ & $\begin{array}{c}3 \text { men- } \\
\text { tions }\end{array}$ \\
\hline $\begin{array}{l}\text { Personal } \\
\text { value } 1\end{array}$ & $\begin{array}{l}\text { One, obviously it's a bachelor, engineering degree. That's really good. And it's within the health care... I } \\
\text { think that longer term when it comes to how it's going to look on paper for my career, I think that it's } \\
\text { not really going to matter too much between if I got a BME degree or if I got an IOE degree for my } \\
\text { undergrad. Because I think that's been the main thing that I've been thinking about is like "Man, did I } \\
\text { sort of waste my time doing this BME degree when I'm ending up going more down the operations } \\
\text { route and doing sort of IOE type stuff?" P6I3 } \\
\text { [talking to a mentor about completing the BME degree and pursing nursing after completion or switching } \\
\text { majors in their third year] And he [the mentor] said that part of the value in finishing an engineering } \\
\text { degree instead of switching to nursing - at that time, cause that's what I was talking about just } \\
\text { changing majors - that it shows that you can just take a lot... and that you can weep over the hardest } \\
\text { problem and then come back to work the next day. And that's kind of what's been pulling me through } \\
\text { this because I'm not really sure. I think that for where I'm headed, I think that my degree shows that I } \\
\text { have some ability to understand technical problems. P10I3 }\end{array}$ & $n=7$ & $n=1$ \\
\hline $\begin{array}{l}\text { Personal } \\
\text { value } 2\end{array}$ & $\begin{array}{l}\text { I feel like it's like an engineering degree on its own from [Study's University] is super valuable. I think } \\
\text { people see that and they know how the curriculum is and just how much work it is and how well you } \\
\text { have done to get that in the first place. I don't really know about specifically the BME degree I would } \\
\text { assume it's similar, we're top } 10 \text { consistently in BME, so I'm assuming that would give me an edge in } \\
\text { grad school. P3I2 }\end{array}$ & $n=6$ & $n=1$ \\
\hline $\begin{array}{l}\text { Personal } \\
\text { value } 3\end{array}$ & $\begin{array}{l}\text { I think it's really important to study something that you're genuinely interested in. I knew that I wanted to } \\
\text { do engineering. Engineering itself is such a hard curriculum, I honestly don't think I could get through } \\
\text { four years of, because hearing BMEs might not be valued as much as a mechanical engineer or } \\
\text { whatever for a mechanical job, I genuinely don't think I would have been interested enough in those } \\
\text { classes without having the biology aspect of it and helping people aspect of it pushing me through } \\
\text { hard stuff. I think by liking my classes and liking what I'm doing, that just makes me a better possible } \\
\text { employee too. P12l1 }\end{array}$ & $n=5$ & $n=3$ \\
\hline
\end{tabular}


Unique Skill 1: Understand how human biology impacts a problem.

Unique Skill 2: Communicate across the disciplines involved in problem solving or definition.

Unique Skill 3: Bring together multiple disciplinary perspectives to solve a problem.

Unique Skill 4: Be open and accepting of the value of collaboration when problem solving.

Participants discussed the ability to understand how human biology can impact a problem (Unique Skill 1) and to bring multiple disciplinary perspectives together (Unique Skill 3) most frequently of the four skills identified. Table 4 shows example quotes of each skill along with the number of participants who discussed that skill in at least one interview or across all three interviews.

\section{The Perceptions of a BME Degree that can Affect Career Placement}

When discussing the difficulties that BME graduates face when applying for BME jobs, students often described perceptions of a BME degree that could lead to difficulties securing a job. These perceptions related to competition with other engineers who apply for the same jobs (e.g., mechanical, electrical, and chemical)
(Perception 1), the disciplinary breadth of their required coursework (Perception 2), and the breadth of possible careers that BME graduates can enter (Perception 3). When discussing these perceptions, participants also frequently reframed the conversation by naming ways they might interpret them more positively. For example, students discussed misconceptions of what BME graduates know and the perception that it is easier to teach mechanical engineering (ME), electrical engineering (EE), or chemical engineering $(\mathrm{ChE})$ graduates biology concepts than to teach BMEs deeper technical skills. However, they also discussed strategies for competing with other engineers by emphasizing BME graduates' communication skills, ability to work on interdisciplinary teams, and understanding of the human aspects of a problem in interviews. Similar pro and con discussions occurred when students talked about the breadth of their curriculum and career options upon graduation. Students' descriptions related to this focus area often intertwined multiple themes within the same section of their discussion. For example, in Interview 2, Participant 3 described the value of their degree like this:

I don't know, the BME degree in itself [...] in general is still new. And that people don't really

TABLE 4. Examples of participant claims of unique skills gained through a BME degree.

\begin{tabular}{|c|c|c|c|}
\hline Theme & Example quote & $\begin{array}{l}1+\text { men- } \\
\quad \text { tion }\end{array}$ & $\begin{array}{c}3 \text { men- } \\
\text { tions }\end{array}$ \\
\hline $\begin{array}{l}\text { Unique } \\
\text { skill } 1\end{array}$ & $\begin{array}{l}\text { I know [my BME degree] would be valuable to a good team of, just a variety of engineers, just because, as } \\
\text { I mentioned earlier, we do have a lot of the similar skills as other types of engineers, but we do have a } \\
\text { deeper understanding of biological processes, and how to apply the basic engineering to the human } \\
\text { body, which is obviously essential. P8I1 } \\
\text { I'd probably tell them that I understand how to work on the human body applications of various... I can't } \\
\text { say things. Just various products, so drugs, prosthetics, or just things that help the body from the } \\
\text { outside, can help with devices that take measurements from the body. Yeah. Or just engineering other } \\
\text { things to mimic the body. P7I1 }\end{array}$ & $n=8$ & $n=3$ \\
\hline $\begin{array}{l}\text { Unique } \\
\text { skill } 2\end{array}$ & $\begin{array}{l}\text { So, I think BME is a mix between a lot of different majors. In order to be good at BME, you need to be able } \\
\text { to have a wide range in knowledge. You're not going to be the most depth at a certain topic, but you } \\
\text { have the breadth to communicate between electrical engineers, mechanical engineers on the goal of a } \\
\text { project. P5I1 }\end{array}$ & $n=8$ & $n=0$ \\
\hline $\begin{array}{l}\text { Unique } \\
\text { skill } 3\end{array}$ & $\begin{array}{l}\text { I think that biomedical engineers have... a very good ability to draw together ideas and concepts from } \\
\text { different disciplines, and apply to engineering design and innovation. Just because while other engi- } \\
\text { neering disciplines, yes, they have to draw together different things that they learn in discrete courses. } \\
\text { BMEs are really working at the intersection of human life and engineering. So, I think that the practice } \\
\text { that we get in our education and through [co-curriculars], help us to use skills in drawing together } \\
\text { interdisciplinary fields, not just for BME purposes, but in general, just like blurring the distinct lines that } \\
\text { are often drawn between different fields. P14l1 }\end{array}$ & $n=12$ & $n=5$ \\
\hline $\begin{array}{l}\text { Unique } \\
\text { skill } 4\end{array}$ & $\begin{array}{l}\text { Just the experience, not only in the classes that are offered in BME, of being interdisciplinary themselves, } \\
\text { but also the opportunities of working with other disciplines and understanding the key core concepts, in } \\
\text { working with them and hopefully in the actual physical sense of building something or creating } \\
\text { something or programming or CADing something. That exposure and experience gives BMEs a lot of } \\
\text { advantage in working in interdisciplinary teams and contexts. P1I2 }\end{array}$ & $n=3$ & $n=1$ \\
\hline
\end{tabular}


know what it means to be BME unless you're in BME, and so I feel like that makes it less valuable than [a] mechanical engineering degree [...] I feel it's going to get better [...] as people get more familiar and the field is going to blow up, I think but as of now, I just feel like that's why people do grad school because it's you need to be able to focus on something [...] to be like, "Yeah, I'm an expert at this, hire me because I know everything about this," versus like, "I'm BME," I know a lot about a lot of different things you can teach me things I could work for you whatever, but it's... I feel like having a grad degree in BME is more valuable.

When prompted further to describe the value in the workplace this participant added:

I feel like if you compare a BME degree to aerospace or something it's like where can an aerospace engineer work? You can work on planes or on rockets, that's it. Versus, BME you can work, consulting, tech companies, I didn't even know Apple hires BMEs, they hire BMEs it to work on fitbits and stuff, Google, Nike, all these things that you wouldn't think of that I've learned and I'm sure it's not like you're competing [...] a mechanical engineer can't do the job of a BME In Apple, you can't. Those are things that are specific to the BMEs and I think that's pretty valuable [...] I think just it's broad enough that it gives you options.

The participant then went on to discuss what makes BME students unique by saying:

I feel like we have to take a lot of random prerequisites that diversify our way of thinking, it's not just re-engineering stuff, the fact that we have to take orgo, biochem, all of the calcs [...] We are prepared for med school because we can do the memorization, brute learning kind of thing that [other college within the university] kids do, but also we have that logic way of thinking [...] BMEs I know do really well at orgo. And [other college within the university] kids are like, "That's our hardest class, oh my God it's awful," but it's just because we're good at pattern recognition, we're good at... It's not memorization, it's just like, oh, you see this and oh, the next thing would be this and [...] it's more the way that engineers think. I think that's what we have, but we also have the random memorization facts thing that, I feel like other majors wouldn't have [...] I just think the chem stuff is just random memorization that you wouldn't necessarily get as an other engineer that... Just valuable knowledge, I guess on other things that are more applicable.

In this example, Participant 3 discussed both positive and negative interpretations of the perception that BME graduates compete with other engineers for BME jobs, but they also added ways to frame their degree positively that related to perceptions of breadth at a cost of depth in disciplinary knowledge and breadth in possible career paths upon graduation. During the interviews, study participants shared both negative and positive perceptions about how their BME undergraduate degree might affect their career placement. These discussions were often complex and interrelated. As such, the research team developed a set of statements, presented in Table 5, that represent these perceptions. Positive interpretations of the perceptions are presented in the right column and negative interpretations are presented in the left column. These statements are not direct quotes from participants but rather the researchers' interpretations of different kinds of perceptions shared by participants.

\section{DISCUSSION}

In this study, the research team explored how students discussed the value of their BME degrees and their motivations for pursuing BME. We found three areas of focus in participants' discussions: (1) personal value of the degree, (2) unique skills BME graduates have, and (3) perceptions of BME graduates. Students found the degree valuable for personal reasons, not necessarily linked to attaining BME careers, but more related to their persistence in the degree. They described a set of professional skills they felt were important and unique to BME graduates, and they discussed the how they felt earning a BME undergraduate degree was perceived. Based on the themes identified in the three focus areas and the literature reviewed, implications for changes in practice and suggested research topics that warrant further investigation are proposed.

\section{The Personal Value of an Undergraduate BME Degree}

Participants indicated that they valued BME because it allowed them to study something they find important or interesting within engineering. This finding proposes a potential motivation that draws students to BME apart from industry-centric, careerrelated motivations frequently studied in engineering. Apart from Potvin and collaborators' work, ${ }^{26}$ very few 
TABLE 5. Participant perceptions of how a BME degree can affect career placement.

Perception 1: Biomedical engineers compete with other engineers for biomedical engineering jobs

$(-)$ It is easier to teach biology to an engineer than technical engineering content to a biomedical engineer

(-) People do not know what a biomedical engineer is taught so they have unrealistic expectations

$1+$ mention $(n=8)$

3 mentions $(n=0)$

Perception 2: Biomedical engineers learn a breadth of disciplinary con
$(-)$ It is difficult to demonstrate how a biomedical engineer's broad exposure aligns with a specific career path

(-) Broad disciplinary exposure requires many introductory classes and pushes back exposure to classes that teach technical, career relevant skills

$1+$ mention $(n=9)$

Perception 3: Career options for biomedical engineers are very broad

$(-)$ There are so many career options for a biomedical engineer. Where do I start?

(-) If I try to focus on one part of BME to be more aligned with a career, what happens if I dislike it?

$1+$ mention $(n=4)$

3 mentions $(n=0)$

studies have explored these motivations in BME students. Understanding this motivation and identifying other non-career related motivations for pursuing $\mathrm{BME}$ can contribute to recruitment and retention efforts in BME programs. Additionally, all three of the participants who consistently mentioned this motivation had at least one marginalized identity within engineering (further identity details omitted to protect participants' identities). Given that BME has been recognized for attracting more diverse students, particularly women, ${ }^{21}$ this finding warrants distinct examination in future studies. Future research in this area should not only focus on how BME attracts diverse students, but given recent research that indicates that students may not pursue engineering jobs upon graduation, ${ }^{7,17,29}$ studies should also examine patterns in how diverse students exit the degree program, paying particular attention to what careers they pursue and why.

\section{The Unique Skills Gained Through a BME Degree}

Participants viewed the unique skills of BME graduates as linked to problem solving, particularly their ability to: (1) understand the human biology context of a problem, (2) communicate across disciplines, (3) bring together multiple disciplinary perspectives, and (4) be open and accepting of the value of collaboration. Other research has examined the perceptions of what skills other stakeholders (e.g., industry employers, academic employers, educators) expect
(+) Biomedical engineers bridge the gap between disciplines on interdisciplinary teams because they are able to communicate between them

(+) Biomedical engineers have a better understanding of the human biology side (patients, other stakeholders) of a problem

$1+$ mention $(n=6) \quad 3$ mentions $(n=0)$

ncepts, but none in depth

(+) The broad curriculum gives a biomedical engineer freedom to tailor their experience to specific interests (e.g., courses, co-curriculars)

(+) The subject matter relates to human or biology problems which keeps some students interested in pursuing engineering

$1+$ mention $(n=9)$

3 mentions $(n=0)$

(+) I came in with a perception that BME career options are broad, but that perception has broadened further as I progress

(+) Focusing on a specific sector of BME careers with courses and cocurriculars makes one more competitive

(+) A BME degree gives you flexibility after graduation to try a career path and if you do not like it, try something different

$1+$ mention $(n=11) \quad 3$ mentions $(n=2)$ from BME students in an effort to inform curricula. ${ }^{20,21,28,36}$ An article by Rivera and colleagues compared the desired skills of academic and industry employers finding that both academic and industry sectors emphasize professional skills more than technical skills, BME conceptual knowledge, or specific experiences. ${ }^{28}$ In looking at specific professional and technical skills mentioned by the interviewees in their study, they also found that the expectations did not align between industry and academic stakeholders and suggested that more opportunities should be created for students to develop the variety of professional and technical skills needed to be successful in BME. Given that the skills identified by the students in this study align partially with those identified in previous academics' efforts, ${ }^{1,20,21,28,36}$ but do not comprehensively cover them, future research may wish to examine how students determine what they consider career-relevant skills or how departments can help students communicate how the unique skills they develop as a BME student align with specific employer priorities.

\section{The Perceptions of a BME Degree that can Affect Career Placement}

Students' expectations about exploring career options post-graduation included: (1) Biomedical engineers compete with other engineers for biomedical engineering jobs, (2) Biomedical engineers learn a breadth of disciplinary concepts, but none in depth, and (3) Career options for biomedical engineers are 
very broad. These perceptions were highly aligned with longstanding discussions in BME education. 2,3,24 Given the persistence of these views in the discipline, researchers and educators should consider different approaches to understanding and addressing the problems students encounter with how BME is perceived as it relates to career placement. Two questions to consider are:

1. What resources, educational opportunities, workshops, etc. should be incorporated into the BME undergraduate experience to help BME students market themselves for a career? What might those additions look like (e.g., length, format, etc.)? One example of an addition universities have implemented with success is the co-op and internship industry partnerships described by Reference 35, but resources for students who cannot participate in internships or do not aim to pursue industry should also be considered in the development of career-related educational efforts.

2. How could departments facilitate opportunities for undergraduate students to explore careers outside of those currently considered conventional for BME graduates (e.g., industry, medical, or other graduate school)? In another article, career discussions from the same participants interviewed in this study were explored. Findings from that study give preliminary insights on what career exploration opportunities looked like for students at their university. ${ }^{13}$

Finally, in looking at how educators might help students positively interpret the perceptions of BME graduates, it may be helpful to use the interpretations that students in this study used to reframe the perceived barriers to BME career placement as summarized by the research team in Table 5. Despite acknowledging the negative stereotypes of a BME undergraduate degree, participants were able to communicate how that stereotype could also be beneficial in a professional setting or in the job search process. Educators or advisors may use these reframing strategies to facilitate conversations with students struggling with a job search.

\section{Limitations}

In most cases, qualitative research does not aim to be generalizable, ${ }^{9,23}$ and as such, the findings in this study may not encompass all of the perspectives of the general BME student population. Instead, this work contributes to educators' and researchers' understanding of the BME student experience in a different way. The in-depth discussions examined over time in this study allowed for the identification of common student experiences that had not been explored in previous research, make recommendations about practices that could benefit students' career exploration experiences in BME, as well as make recommendations for future research based on the patterns identified in this exploratory work. The students interviewed in this study represent a subset of students in BME programs, but the commonalities identified across their experiences are worth investigating in future research and other contexts. Research that includes students in different stages of their degree program (e.g., first year, second year, graduate-level students, etc.), that expands representations of students of different racial or ethnic backgrounds, and that includes different institutions might map to the three focus areas identified in this study, verifying these experiences in new contexts. This research could also identify additional patterns of discussion that further expands the understanding of students' perceptions of a BME undergraduate degree. Most notably, further exploration of the experiences and perceptions of BME students who hold marginalized identities is needed to understand their perceptions of the personal value of the BME degree.

\section{CONCLUSIONS}

In this study, the reasons for pursuing their degree and the career perceptions of students with a BME undergraduate degree were explored through interviews of a cohort of third-year BME students. Results of this study suggest future research to explore how students move through BME programs in relation to career paths, how students and programs communicate the unique skills students develop through BME undergraduate programs, and how programs can help students explore career opportunities in the field.

\section{ACKNOWLEDGMENTS}

The authors would like to thank the participants in this study for their thoughtful reflections on their BME experiences.

\section{AUTHOR CONTRIBUTIONS}

$\mathrm{CJ}, \mathrm{AH}-\mathrm{S}, \mathrm{SD}$, and LL contributed to the study conception and design. Data collection and analysis were performed by $\mathbf{C J}$ and AW, with feedback from AH-S throughout. The first draft of the manuscript was written by $\mathrm{CJ}$ and all authors commented on previous versions of the manuscript. All authors read and approved the final manuscript. 


\section{FUNDING}

This work was supported by the University of Michigan through the Rackham Merit Fellowship, a Rackham Graduate Student Research Grant, and the Undergraduate Research Opportunity program.

\section{DATA AVAILABILITY}

Due to the small sample size and in-depth nature of these interviews, participants could potentially be identifiable in the full dataset. Coded, deidentified data is available upon request to protect the confidentiality of participants.

\section{CONFLICT OF INTEREST}

The authors have no conflicts of interest to declare that are relevant to the content of this article.

\section{ETHICAL APPROVAL}

Approval of this work as an exempt study was obtained from the institutional review board at the University of Michigan under IRB HUM00168130.

\section{CONSENT TO PARTICIPATE}

Informed consent was obtained from all individual participants included in this study.

\section{CONSENT FOR PUBLICATION}

Informed consent was obtained from all individual participants whose quotes were used in this study.

\section{REFERENCES}

\footnotetext{
${ }^{1}$ Abu-Faraj ZO. Bioengineering/biomedical engineering education and career development: literature review, definitions, and constructive recommendations. Int $\mathbf{J}$ Eng Educ 2008;24(5):990-1011.

${ }^{2}$ Berglund $\mathbf{J}$. The great divide: some worry of a gap between what is being taught in American university undergraduate BME programs and the job market. IEEE Pulse 2015;6(2):42-5.

${ }^{3}$ Berglund J. The real world: BME graduates reflect on whether universities are providing adequate preparation for a career in industry. IEEE Pulse 2015;6:46-9.

${ }^{4}$ Borrego M, Douglas EP, Amelink CT. Quantitative, qualitative, and mixed research methods in engineering education. J Eng Educ 2009;98(1):53-66.

${ }^{5}$ Case JM, Light G. Emerging methodologies in engineering education research. J Eng Educ 2011;100(1):186-210.
}

${ }^{6}$ Gatchell D, Linsenmeier R. VaNTH Biomedical Engineering Key Content Survey, Part Two. The 2nd Step in a Delphi Study to determine the core undergraduate BME curriculum. In: Am. Soc. Eng. Educ.; 2007.

${ }^{7}$ Gilmartin SK et al. Chapter 2: Career Plans of Undergraduate Engineering Students: Characteristics and Contexts. In: U. S. Engineering in the Global Economy, April 2015, p. 1-69.

${ }^{8}$ Guilford WH. Clinician-engineer career bias and its relationship to engineering design self-efficacy among Biomedical Engineering undergraduates. In: ASEE Annual Conference and Exposition, Conference Proceedings; 2020.

${ }^{9}$ Hesse-Biber SN. The practice of qualtitative research: engaging students in the research process. 3rd ed. London: SAGE Publications' 2017.

${ }^{10}$ Hsieh HF, Shannon SE. Three approaches to qualitative content analysis. Qual Health Res 2005;15(9):1277-88.

${ }^{11}$ Huang-Saad A, Stegemann J., Shea, L. Developing a model for integrating professional practice and evidence-based teaching practices into BME curriculum. Ann Biomed Eng 2020;48(2):881-92.

${ }^{12}$ Jamison C, Huang-Saad A, Daly S, Lattuca L. The value of co-curricular experiences: perspectives of third-year biomedical engineering students. In: Amercian Society for Engineering Education Annual Conference and Exposition; 2020.

${ }^{13}$ Jamison, CSE, Wang AAM, Huang-Saad AY, Daly SR, Lattuca LR. BME career exploration: examining students' career perspectives,. In: ASEE Annual Conference Proceedings; 2021.

${ }^{14}$ Katona PG. Biomedical engineering and the whitaker foundation: a thirty-year partnership. Ann Biomed Eng 2006;34(6):904-16.

${ }^{15}$ Lattuca LR, Knight DB, Bergom IM. Developing a measure of interdisciplinary comptence for engineeers. In: American Society for Engineering Education; 2012, p. 119.

${ }^{16}$ Leydens JA, Moskal BM, Pavelich MJ. Qualitative methods used in the assessment of engineering education. J Eng Educ 2004;93:65-72.

${ }^{17}$ Lichtenstein G, Loshbaugh HG, Claar B, Chen HL, Jackson K, Sheppard SD. An engineering major does not (necessarily) an engineer make: career decision making among undergraduate engineering majors. J Eng Educ 2009;98(3):227-34.

${ }^{18}$ Linsenmeier RA. What makes a biomedical engineer? IEEE Eng Med Biol Mag 2003;22(4):32-8.

${ }^{19}$ Linsenmeier RA. What makes a biomedical engineer? Annu Rev Biomed Eng 2003;4:2000.

${ }^{20}$ Linsenmeier RA, Gatchell DW. Core elements of an undergraduate biomedical engineering curriculum - state of the art and recommendations; 2006. p. 22-4.

${ }^{21}$ Linsenmeier RA, Saterbak A. Fifty years of biomedical engineering undergraduate education. Ann Biomed Eng 2020;48(6):1590-615.

${ }^{22}$ Merriam SB. Designing your study and selecting a sample,. In: Qualititative Research: A Guide to Design and Implementation; 2009.

${ }^{23}$ Merriam SB. Qualitative research: a guide to design and implementation. 2nd ed. San Francisco: Jossey-Bass; 2009.

${ }^{24}$ Nocera TM, Ortiz-Rosario, A, Shermadou A, Delaine DA, Delanine D, Delaine DA. How do biomedical engineering graduates differ from other engineers? Bridging the gap between BME and industry: a case study. In: ASEE Annual 
Conference and Exposition, Conference Proceedings; 2018, p. $1-7$.

25“NVivo Version 12” [Online]; 2018. Available: https://ww w.qsrinternational.com/nvivo-qualitative-data-analysis-sof tware/home/.

${ }^{26}$ Potvin G. et al. Gendered interests in electrical, computer, and biomedical engineering: intersections with career outcome expectations. IEEE Trans Educ 2018;61(4):298-304/.

${ }^{27}$ Ramo NL, Huang-Saad A, Belmont B. What is biomedical engineering? Insights from qualitative analysis of definitions written by undergraduate students. In: ASEE Annual Conference and Exposition, Conference Proceedings; 2019.

${ }^{28}$ Rivera CP, Huang-Saad A, Woodcock CSE, Wang AAM. Preparing early career biomedical undergraduates through investigations of stakeholder needs: a qualitative analysis. In: ASEE Annu. Conf. Expo. Conf. Proc., vol. 2020-June; 2020.

${ }^{29}$ Rohde JA et al. Investigating the intersection of career aspirations and engineering beliefs in first year engineering students. In: roc. - Front. Educ. Conf. FIE, vol. 2018-October, no. 1428689; 2019.

${ }^{30}$ Rohde J, France J, Benedict B, Godwin A. Exploring the early career pathways of degree holders from biomedical, environmental, and interdisciplinary/multidisciplinary engineering. In: ASEE Annual Conference and Exposition, Conference Proceedings; 2020, vol. 2020-June.

${ }^{31}$ Ropella KM. Biomedical engineering: the career of choice. IEEE Eng Med Biol Mag 200322:23-5.

${ }^{32}$ Saldana J. The coding manual for qualitative researchers, 3rd ed. London: SAGE Publications Ltd; 2016.

${ }^{33}$ Saldaña J, Omasta M. Qualitative research analyzing life. 1st ed. London: SAGE Publications; 2018.

${ }^{34}$ Walther J. et al. Qualitative research quality: a collaborative inquiry across multiple methodological perspectives. J Eng Educ 2017;106(3):398-430.

${ }^{35}$ Waples LM, Ropella KM. University-industry partnerships in biomedical engineering. IEEE Eng Med Biol Mag 2003;22(4):118-21.

${ }^{36}$ White JA et al. Core competencies for undergraduates in bioengineering and biomedical engineering: findings, consequences, and recommendations. Ann Biomed Eng 2020;48(3):905-12.

Publisher's Note Springer Nature remains neutral with regard to jurisdictional claims in published maps and institutional affiliations. 